\title{
"Reconstruyendo" una ruina del siglo XVII. El desaparecido convento de la Encarnación de Mondoñedo
}

\author{
"Rebuilding" a ruin of the seventeenth century. \\ The Missing Convent of the Incarnation from Mondoñedo \\ JAVIER GÓMEZ DARRIBA \\ Universidade de Santiago de Compostela \\ javier.gomez.darriba@usc.es \\ http://orcid.org/0000-0001-6712-2983 \\ http://dx.doi.org/10.15304/sm.31.5994
}

\section{RESUME}

El presente trabajo tiene como objetivo describir la morfología del desaparecido convento mindoniense de la Encarnación. Este se levantó sobre la falda de una colina a las afueras de la ciudad en la década de 1650 y se demolió sesenta años después por causa de su nefasta construcción. Asimismo se dará noticia de los maestros de obras que lo erigieron -Diego Ibáñez Pacheco y Antonio Rodríguez Maseda-, de los canteros que trabajaron a sus órdenes e incluso de otros arquitectos que inspeccionaron su ruina, caso de fray Gabriel de Casas entre otros.

Palabras clave: Arquitectura gallega del siglo XVII, Diego Ibáñez Pacheco, Antonio Rodríguez Maseda, fray Gabriel de Casas, Bernabé García de Seares.

\section{Abstract}

The objective of this work is to describe the morphology of the vanished Convento de la Encarnación of Mondoñedo, built on a hill outside the city in 1650s and demolished sixty years later because of a disastrous construction. We will also give news about the masters builders who erected it -Diego Ibáñez Pacheco and Antonio Rodríguez Maseda-, the stonemasons who worked under his orders and even other architects who inspected its ruin -fray Gabriel de Casas among others-. Keywords: Galician architecture of the $17^{\text {th }}$ century, Diego Ibáñez Pacheco, Antonio Rodríguez Maseda, fray Gabriel de Casas, Bernabé García de Seares.

\footnotetext{
* Grupo de investigación GI-1510 HAAYDU de la Universidade de Santiago de Compostela, del que es
} coordinador Alfredo Vigo Trasancos. 


\section{INTRODUCCIÓN}

La mayor parte de los monasterios españoles que no han sobrevivido a nuestros días deben su desaparición a las políticas desamortizadoras del siglo XIX o a conflictos bélicos habidos entonces y entre 1936-1939. Pero el caso que nos ocupa en este estudio es bien distinto, pues la causa de que el primitivo convento concepcionista de Mondoñedo se volatilizase a inicios del XVIII cuando apenas llevaba medio siglo en pie responde sencillamente a la mala praxis del arquitecto que lo diseñó, a la escasa pericia de los maestros que lo construyeron y a la desidia y racanería de los patronos que se vieron obligados a erigirlo.

Nuestro propósito es "reconstruir" la morfología de aquel cenobio y dar a conocer la autoría del proyectista, aparejadores y canteros que contribuyeron a levantar un edificio que ya presentaba problemas tectónicos desde el momento en que se estrenó. Para llevar a cabo esta labor hemos acudido a distintos archivos en los que por desgracia no hemos hallado documentación gráfica como pudieran ser la planta y alzados originales. Tampoco hemos encontrado ninguna escritura relacionada con el contrato de las condiciones de la obra. Estas ausencias sorprenden enormemente porque la historia del convento va intrínsecamente ligada a la deficiente manera en que se construyó, y, en consecuencia, gran parte de la documentación relativa a él, caso de pleitos, fundaciones abortadas, informes periciales, etc., tiene su origen en el mal estado de su edificación. De todos modos contamos con una infinidad de datos que nos permiten describir cómo era aquella casa monástica y quiénes levantaron semejante ruina.

\section{NI BETANZOS, NI PONTEDEUME NI VIVEIRO. MONDOÑEDO COMO LUGAR DE FUNDACIÓN}

Todo tiene su comienzo en septiembre de 1622. Entonces, María Pardo de Andrade, residente en Viveiro y viuda del oidor Agustín Guedeja, se concertó con las dominicas de aquella villa en trasladar el convento de Nuestra Señora de Valdeflores al interior del recinto amurallado. En caso de no resultar factible esta mudanza lo conduciría hasta la ciudad de Betanzos, e independientemente de cuál fuese su destino se construiría siguiendo unos planos de los maestros Diego Ibáñez Pacheco y Juan de Ris. Lo pondría bajo la advocación de la Encarnación y en él ingresarían un total de 40 monjas. La donante se inhumaría en la capilla mayor y colocaría en ella su escudo de armas, derecho que también tendrían sus herederos, quienes conservarían el patronato del cenobio siempre y cuando le asignasen 600 ducados anuales. Al año siguiente se aprobó la instalación en el Viveiro intramuros y en 1627 dieron comienzo las obras, que se suspendieron de inmediato después de que el Consistorio le ganase un pleito a la 
fundadora ${ }^{1}$. Aun así María Pardo no cejó en el empeño de instaurar un convento de la Encarnación en su localidad de residencia, y el 12 de mayo de 1635 se convino nuevamente con Diego Ibáñez para que por 62.700 reales construyese el nuevo monasterio de Valdeflores en el interior del espacio amurallado, concretamente en un solar que tenía en la Rúa de Labrada ${ }^{2}$. Pero el proyecto quedó abortado por segunda vez. Ignoramos por qué, aunque es posible que, como en el primer intento, se produjeran diversas discrepancias con el vecindario y el Concejo que derivasen en su pronta interrupción.

Y decimos pronta porque si en agosto de 1635 Diego Ibáñez tenía encomendado iniciar las obras, pasados diez meses se leía en Madrid una petición de la donante por la que pretendía fundar ese mismo convento en la villa de Pontedeume. Quizá para evitar los problemas sufridos en Viveiro permitiría al Ayuntamiento eumés elegir el lugar donde se edificaría. En esta ocasión no lo regirían las dominicas sino la Orden de la Inmaculada Concepción, cuyas primeras monjas en instalarse provendrían de Viveiro por hallarse allí la única casa concepcionista de Galicia. Por lo demás acogería un máximo de 30 religiosas, la donadora y su familia podrían enterrarse en la capilla mayor, y los legatarios conservarían el patronato bajo la asignación de 650 ducados de renta anual. En definitiva, en enero de 1637 todo parecía encarrilado, pues María Pardo de Andrade escrituraba la fundación tras haber obtenido la licencia real pertinente ${ }^{3}$. Pero pasaron los meses y en octubre de 1639 cayó gravemente enferma. Residía entonces bajo los cuidados de una sobrina en Mondoñedo, e hizo un testamento en el que ratificó las cláusulas de fundación firmadas dos años antes. Eso sí, con la salvedad de que el convento ya no se levantaría

1 A. Pardo Villar, (1947): «El Convento de Nuestra Señora de Valdeflores. (Apuntes históricos)», Boletín de la Comisión provincial de Monumentos Históricos y Artísticos de Lugo, III, 23-24, pp. 33-35; C. C. Rodríguez Núñez, (1993): «El monasterio de Nuestra Señora de Valdeflores de Viveiro», Estudios Mindonienses, 9, pp. 461-462.

2 Archivo Histórico Provincial de Lugo (A.H.P.L.), Protocolos Notariales de Viveiro (P.N.V.), Antonio Díaz Labrada, leg. 2844-1, ff. 45r - 52v. La antigua Rúa de Labrada se conoce hoy como Irmáns Ponte, J. Donapétry Iribarnegaray, (1953): Historia de Vivero y su concejo, Vivero, p. 300.

3 A.H.P.L., P.N.V., Luis de Santaballa, leg. 4032-3, ff. 14r - 19r; A. Couceiro Freijomil, (1944): Historia de Puentedeume y su comarca, s.1., pp. 362, 364-366; A. López Calvo, (1994): «El frustrado convento de la Encarnación de Pontedeume, un antecedente del convento concepcionista de Mondoñedo», Estudios Mindonienses, 10, pp. 434-439. Efectivamente, el convento inmaculista de Viveiro fue el primero de dicha Orden en el Reino de Galicia. Lo fundó en 1601 María de las Alas Pumariño, J. Donapétry Iribarnegaray, (1947): «Doña María de las Alas Pumariño, fundadora del Convento de la Concepción de Vivero», Boletín de la Comisión provincial de Monumentos Históricos y Artísticos de Lugo, II, 21-22, pp. 299-301; C. Adrán Goás, S. F. Pardo de Cela, (2001): «La fundación del monasterio de la Inmaculada Concepción Francisca de Viveiro», in S. L. Pérez López (coord.), El Monasterio de la Concepción, Viveiro, pp. 65-70, 105-120 (existe copia de este trabajo en Estudios Mindonienses, 17). Cabe resaltar que en la España del siglo XVI se fundaron 71 conventos de esta Orden y en el XVII unos 33, J. García Oro, (2001): «La concepción de Viveiro en su contexto religioso. Un hogar mariano para la Galicia del Barroco», in S. L. Pérez López (coord.), El Monasterio de la Concepción, Viveiro, p. 49. Sobre todos ellos véase M. de Castro, (1991): «Los monasterios de concepcionistas franciscanas en España», Archivo Ibero-Americano, 203-204, pp. 411-477. 
en Pontedeume, sino extramuros de la ciudad en la que ahora vivía, concretamente en el Campo de Nosa Señora de Os Remedios ${ }^{4}$.

Varias han sido las razones argumentadas a la hora de justificar la elección de la urbe episcopal en detrimento de la villa costera. Desde luego el Concejo eumés no tuvo culpa alguna de su decisión, pues aparte de no poner trabas a la fundación ordenó indagar los motivos por los que había renunciado a erigirlo allís. Por suerte en su testamento explicó de forma meridiana los porqués. Expresó que pese a haber dado poderes a su sobrino político Tomás Maldonado y al conde de Lemos con vistas a erigirlo en Pontedeume, surgieron ciertas diferencias entre ambas partes que impidieron llegar a un acuerdo. Señaló también que fundar actualmente conventos en localidades marítimas equivalía a poner en peligro la vida de las monjas dado el riesgo de invasión que sufría el litoral gallego. Dijo por último que deseaba que la comunidad estuviese sujeta al obispo de Mondoñedo, ciudad que era más barata -inclusive en lo que a materiales de construcción se refiere-, y que además contaba con médico, cirujanos y botica que velarían con mayor eficiencia por la salud de las religiosas ${ }^{6}$.

Aparte de las ventajas que según la fundadora ofrecía Mondoñedo, creemos que existían más criterios económicos a los ya mencionados para que prefiriese asentarse en aquella ciudad, e incluso alguno de tipo devocional. Así, según la escritura, existía un acuerdo verbal con el obispo Gonzalo Sánchez de Somoza con vistas a disponer la casa conventual junto a la ermita de Os Remedios, de patronato episcopal desde su erección a mediados del $\mathrm{XVI}^{7}$. Lógicamente esta iglesia pasaría a formar parte del complejo monás-

4 Archivo de la Catedral de Mondoñedo (A.C.M.), Miscelánea (Misc.), arm. 2, est. 1, leg. 8, n. ${ }^{\text {2 }}$, s.f. Este testamento lo dieron a conocer E. Lence-Santar y Guitián, (1910): Mondoñedo: el convento de la Concepción, Mondoñedo, pp. 3-4; y J. Trapero Pardo, (1949): «Un testamento y un inventario de objetos del siglo XVII», Boletín de la Comisión provincial de Monumentos Históricos y Artísticos de Lugo, III, 29-30, pp. 264-267. Del cupo de 30 monjas que cabrían en el convento la mitad serían familiares y parientes de la fundadora. Los futuros patronos conservarían el derecho a elegir otras tantas para su ingreso en la comunidad. Acerca de este sistema de reserva de plazas en los cenobios femeninos véase A. Atienza López, (2008): Tiempos de conventos. Una historia social de las fundaciones en la España moderna, Madrid, pp. 308-326.

5 Buscando dar respuesta a esto, Jesús A. López Calvo adujo distintas hipótesis que nada tienen que ver con lo declarado por María Pardo en su testamento, J. A. López Calvo, (1994): op. cit., pp. 441, 443-445. Por su parte, Manuel de Castro, en una primera publicación en la que desconocía esta escritura, defendió asimismo tesis poco sólidas, M. de Castro, (1995): «¿Por qué el monasterio de las concepcionistas de Mondoñedo no se construyó en Pontedeume?», Estudios Mindonienses, 11, pp. 363-367. En un artículo posterior sí acudió al documento testamentario pero extrajo conclusiones infundadas, cuestionando incluso las cláusulas del manuscrito, Ídem, (2001): «Viveiro, monasterio de la Purísima Concepción», in S. L. Pérez López (coord.), El Monasterio de la Concepción, Viveiro, pp. 168-172 (existe copia de este trabajo en Estudios Mindonienses, 17). Santos San Cristóbal también aportó argumentos sin ningún tipo de apoyo documental, S. San Cristóbal Sebastián, (2001): Monasterio de la Concepción de Mondoñedo, Lugo, p. 22 (la edición original de este libro data de 1978).

6 A.C.M., Misc., arm. 2, est. 1, leg. 8, n. ${ }^{\circ} 2$, s.f.

7 De hecho declaró que el sitio se lo había ofrecido el propio prelado. Por otro lado volvió a manifestar su deseo de ser inhumada en un sepulcro de la capilla mayor con las correspondientes armas y letrero alusivo a su fundación, Archivo del Convento de las Madres Concepcionistas Franciscanas de 
tico. Con lo cual, por escueto o mediano que fuese su tamaño, y aunque los patronos se viesen obligados a financiar una reforma con vistas a aumentar su fábrica arquitectónica, al menos ya contaban con un templo sin necesidad de levantar otro ex novo. Además este no era un recinto mariano cualquiera, sino un santuario de vital importancia en la comarca al que acudían multitud de fieles. Dicho de otro modo, podría constituir un filón para que las rentas del convento se viesen aumentadas, y también para que distintas mujeres de la zona tomasen allí los hábitos y trajesen consigo las dotes correspondientes.

De todos modos el establecimiento en Os Remedios no se hizo efectivo por la tenaz oposición del Cabildo, acostumbrado a impedir cuanta fundación monástica se pretendía en Mondoñedo con la excusa de que sus beneficios se verían diezmados. Consecuentemente María Pardo pidió erigirlo en una propiedad familiar sita en el barrio extramuros de Couto do Outeiro distante «medio cuarto de legua» del núcleo urbano. En aquella finca su heredero y futuro patrono, el capitán y regidor Pedro Fernández Baamonde, había fundado tiempo atrás una ermita dedicada a Nuestra Señora del Socorro ${ }^{8}$. En junio de 1646, estando María difunta, el obispo Juan Juaniz de Echalaz aprobó aquel sitio como lugar destinado a la erección del convento. Y justo diez años después, hallándose las obras casi finalizadas, se otorgó la escritura de fundación.

\section{DE ARQUITECTOS, APAREJADORES Y CANTEROS: LA AUTORÍA DEL CONVENTO}

Pese a que no hemos hallado las trazas del monasterio ni las condiciones en que se remató su obra, sí hemos dado con una serie de datos que nos confirman qué maestros lo levantaron y qué oficiales trabajaron a su lado. Incluso podemos suponer quién se encargó de diseñarlo. Y creemos que dicha competencia recayó en Diego Ibáñez Pacheco. Nacido en 1595 en la localidad cántabra de Noja ${ }^{9}$, constituyó la mayor figura en el campo de la arquitectura en la Mariña Lucense entre las décadas de 1620 y 1660. En honor a la verdad no era más que un simple maestro de cantería -así solía autodenominarse inclusoque ocasionalmente proyectaba y daba condiciones para obras de escasa complejidad y grandeza, como pequeños conventos, iglesias, capillas, sepulcros, claustrillos, arreglos de puentes, etc. La entidad de estas obras se explica porque su humilde clientela no podía

Mondoñedo (A.C.M.C.F.M.), "Traslacion del Convento á Mondoñedo 1.700 á 1.708” (a partir de ahora “Traslacion...”), ff. 100r - 105r; E. Lence-Santar, (1910): op. cit., pp. 3-4.

8 A.C.M., Misc., arm. 2, est. 1, leg. 8, n. ${ }^{\circ}$ 1, f. 2r; A.H.P.L., Protocolos Notariales de Mondoñedo (P.N.M.), Domingo López Traveso, leg. 6865-4, f. 184v; E. Lence-Santar, (1910): op. cit., p. 5. El referido coto lo había adquirido en 1627 Pedro Fernández Baamonde luego de comprárselo a la comunidad benedictina de Vilanova de Lourenzá, ibídem, p. 20. La ermita de Nuestra Señora del Socorro también estaba dedicada a san Isidro Labrador y a la beata María de la Cabeza, y tenía anexa una casa para la ermitaña, A.H.P.L., P.N.M., Antonio Fernández Cedofeita, leg. 7166-1, f. 38v.

9 C. Adrán Goás, (2014): «Regidores del Concejo de Viveiro (siglos XV al XIX)», Estudios Mindonienses, 30 , p. 343. 
acometer empresas mayores. De ahí que estas se presupuestasen en precios muy bajos que el propio Diego se adjudicaba o subcontrataba a discípulos e hijastros suyos, como lo fue Antonio Rodríguez Maseda. Estilísticamente este trasmerano se caracterizó por el empleo de un clasicismo burdamente ejecutado, y tanto su currículum como el devenir de muchas de sus construcciones -así como las de sus discípulos- denotan una evidente torpeza artística y tectónica. Pese a todo su establecimiento en una comarca económicamente deprimida no le granjeó competencia alguna en su profesión, lo que contribuyó a que pudiese llevar una vida acomodada ${ }^{10}$, máxime en sus últimos años, en los que ascendió socialmente gracias a su puesto como regidor de la villa de Viveiro entre 1652 y $1664{ }^{11}$.

La atribución a Diego Ibáñez la fundamentamos en que María Pardo requirió de sus servicios hasta en dos ocasiones para que a partir de sus trazas se llevase a cabo la traslación del convento de Miraflores hasta el sector intramuros de Viveiro. La primera vez en 1622 y la segunda en 1635. De esta última conservamos las condiciones de obra formuladas por el maestro ${ }^{12}$. Consecuentemente no sería de extrañar que volviese a contar con él cuando en 1637 pretendió establecer el cenobio en Pontedeume, o cuando en 1639 quiso erigirlo en Mondoñedo. Además, previo el inicio de las obras, la Iglesia mindoniense recurrió a él para que acudiese hasta el Couto de Outeiro y verificase in situ si aquella propiedad de los Baamonde era idónea o no para la erección de un convento. Así lo hizo el 15 de junio de 1646 acompañado del obispo Juaniz de Echalaz y de miembros del Cabildo. Lógicamente le dio el visto bueno al terreno porque ese mismo día el prelado aprobó que se edificase allí, «pegado a la ermita» del Socorro. Con lo cual, ya solo faltaba que el mitrado recibiese «la planta del tamano que a de ser la division de yglesia, con celdas y mas obras que se an de açer», para a continuación rematarla en «quien con mas comodidad lo hiçiere» ${ }^{13}$. No podemos acreditar documentalmente que dicha planta fuese diseñada por el cántabro, pero desde luego parece lo más probable. De lo que sí hay certeza es que una década más tarde tomó por su cuenta la dirección de las obras con la

10 P. Pérez Costanti, (1930): Diccionario de artistas que florecieron en Galicia durante los siglos XVI y XVII, Santiago, pp. 294-298; A. Bonet Correa, (1966): La arquitectura en Galicia durante el siglo XVII, Madrid, pp. 173-175, 215-217, 531-532; A. Goy Diz, (1996): «La actividad de un maestro cántabro en tierras de Lugo: Diego Ibáñez Pacheco», Altamira, 52, pp. 223-261; M. Taín Guzmán, (1999): «Clasicismo y barroco en tierras mindonienses», Estudios Mindonienses, 15, pp. 478-505; L. Fernández Gasalla, (2004): La arquitectura en tiempos de Domingo de Andrade. Arquitectura y sociedad en Galicia (1660-1712), Santiago de Compostela, pp. 859, 915-931; Ídem, (2008): «La biblioteca del arquitecto Diego Ibáñez Pacheco y la recepción e interpretación de la tratadística italiana en la Galicia Oriental (1623-1694)», en XV Congreso Nacional de Historia del Arte (CEHA). Modelos, intercambios y recepción artística (de las rutas marítimas a la navegación en red). Palma de Mallorca, 20-23 de octubre de 2004, I, Palma de Mallorca, pp. 323-335.

11 Falleció allí mismo en 1666, C. Adrán Goás, (2014): op. cit., p. 344.

12 A.H.P.L., P.N.V., Antonio Díaz Labrada, leg. 2844-1, ff. 48r - 51r.

13 Pasados tres días el Ayuntamiento dio el visto bueno a este acuerdo, A.H.P.L., P.N.M., Domingo López Traveso, leg. 6865-4, ff. 184v - 186v; A.C.M., Actas Capitulares, vol. 12, f. 26r; A.C.M.C.F.M., "Traslacion...", f. 109r; S. San Cristóbal, (2001): op. cit., pp. 21-23; E. Cal Pardo, (2003): Episcopologio mindoniense, Santiago de Compostela, Mondoñedo-Ferrol, p. 520. 
intención de finalizarlas luego de que en los primeros años el grueso de la construcción recayese en su discípulo e hijastro Antonio Rodríguez Maseda ${ }^{14}$.

La primera noticia referente a la edificación del monasterio data del 8 de agosto de 1649. Entonces el referido maestro local Rodríguez Maseda se concertó con un vecino de Santiago de Adelán (Alfoz, Lugo) para que en las dos semanas siguientes le trajese hasta «el conbento q esta aciendo dho ant ${ }^{\circ} \mathrm{r}^{\mathrm{d}}$ maseda» en el Couto de Outeiro siete docenas «de tabla serrada de a treynta y dos palmos la doçena de largo y a ocho de ancho», entre otras maderas ${ }^{15}$. Nada volvemos a saber de la construcción hasta el 21 de septiembre de 1655 . Por aquella fecha el capitán Pedro Fernández Baamonde contrató a cuatro labradores para que quitasen toda «la tierra y rebo» existente en la iglesia puesto que había que embaldosarla. Dicha escritura nos revela que el vecino vivariense Diego Ibáñez «se abia obligado a açer la $\mathrm{ygl}^{\mathrm{a}}$ del convento» y a terminarla «en toda forma quanto a paredes y mas edificios tocantes a canteria». Por entonces el maestro cántabro no se hallaba en Mondoñedo, pero se encargaría de pagar a los campesinos por la citada labor ${ }^{16}$. Asimismo sabemos de la participación del trasmerano en esta obra gracias al ajuste de partijas que tuvo lugar en 1668 entre su tercera esposa Francisca de Neira y su hijastro Antonio Rodríguez Maseda. Su viuda debía entregar al discípulo los 5.557,5 reales que Ibáñez había recibido del capitán Pedro Fernández Baamonde por orden del propio Antonio, y otra cantidad por el «alarife» que había tasado el templo conventual y «la perdida que tubo dha yglessia y açissorias del pleyto que ubo sobre dhas obras los quales gastos le tocaron al dho rregidor diego ybanez conforme a la parte que le toca de dhas obras», dato que ya apunta al escaso rigor con que se efectuaron estas ${ }^{17}$.

Del último párrafo se sobreentiende que en 1655 se estaba concluyendo el monasterio, cuya escritura de fundación se otorgó el 8 de diciembre de $1656^{18}$. Por fortuna contamos con más noticias acerca de los artífices del cenobio gracias a una fuente levemente posterior a su erección, concretamente un pleito celebrado en 1670 entre el obispo Luis Tello de Olivares y el patrono Isidro Alonso Baamonde Pardo y Figueroa. En él varios testigos y colegas atestiguan que Antonio Rodríguez Maseda fue el autor de las obras de «canteria, manposteria y arquitetura» ${ }^{19}$. Dentro de la nómina de canteros que trabajaron a sus órdenes a inicios de la década de 1650 se reseña vanamente la procedencia de algunos diciendo que eran asturianos o vizcaínos. Esta plantilla la conformaban como mínimo

14 Acerca de este maestro de obras véase esencialmente P. Pérez Costanti, (1930): op. cit., pp. 477-480; A. Bonet Correa, (1966): op. cit., pp. 531-532, 535-538; L. Fernández Gasalla, (2004): op. cit., pp. 937-983.

15 A.H.P.L., P.N.M., Juan de Legaspe Barcal, leg. 7316-4, ff. 164r - 164v.

16 Estos tendrían dos meses para desempeñarla y les abonaría 1.100 reales, ídem, Domingo López Traveso, leg. 6865-3, ff. $68 \mathrm{r}-69 \mathrm{r}$.

17 A.H.P.L., P.N.V., Juan de Santaballa y Soto, leg. 2874-7, ff. 2r - 3r. Documento ya citado por L. Fernández Gasalla, (2004): op. cit., p. 928.

18 A.H.P.L., P.N.M., Domingo López Traveso, leg. 6865-4, ff. 184r, 186v - 190r; A.C.M.C.F.M., "Traslacion...", f. 109r.

19 Arquivo do Reino de Galicia (A.R.G.), Real Audiencia (R.A.), leg. 10124-20, ff. 57v y ss, 73r, 78v, 90r, $115 \mathrm{r}, 120 \mathrm{v}$. 
Alonso Branega, Pedro Díaz, Alonso Gutiérrez y Toribio de Noriega ${ }^{20}$. Compartían oficio, vecindad, y seguramente lazos de sangre algunos de ellos. De lo que no cabe duda es que su llegada a la capital episcopal les llevó a contratar por esos años otras obras en la Mariña Lucense aparte de las del convento.

Esto último lo sabemos gracias a otras referencias que nos indican con mayor precisión su procedencia. De tal forma que el aludido Pedro Díaz cabría identificarlo con Pedro Díaz de Noriega, un maestro cantero que en julio de 1654 compareció ante el Consistorio mindoniense declarando ser vecino de las Cuatro Villas de San Vicente de la Barquera $^{21}$. A esta jurisdicción también pertenecía el citado Alonso Gutiérrez, que en diciembre de aquel año se dijo residente en Mondoñedo pero vecino de la Barquera ${ }^{22}$; mientras que en agosto de 1655 especificó que él y su colega Juan Díaz de Noriega se hallaban avecindados en Pimiango (Rivadedeva, Asturias) ${ }^{23}$. No consta que el citado Juan Díaz de Noriega trabajase en el cenobio, y tampoco podemos afirmar que él y Pedro fuesen parientes, aunque dados sus mismos apellidos y la localidad de procedencia lo más seguro es que sí. Del mismo modo desconocemos si compartían vínculos familiares con Toribio de Noriega, un pedrero que, como hemos visto, operó en el convento. Este último personaje cabría identificarlo con Toribio Bueno, pues él y el aludido Juan Díaz de Noriega dijeron en abril y mayo de 1655 «ser vecinos de la primer villa de las quatro de bizcaya y moradores del lugar de pimeango de dho señorio de bizcaya y maestros de arquitetura rresidentes al presente en la $\operatorname{ciu}^{\mathrm{d}}$ de $\operatorname{mon}^{\mathrm{do}} \gg^{24}$.

Ahora bien, en aquellos primeros años de la década de 1650 no solo levantaron el conjunto monástico estos canteros provenientes de la costa cantábrica. Junto a ellos también operó una cuadrilla de pedreros locales entre los que se hallaban Juan Rodríguez, Antonio García da Arqueira, Juan González de Orense, Bartolomé Valiño, o el maestro carpintero Andrés Pardo de Paz, que declaró haber trabajado allí durante tres años ${ }^{25}$. Existe un último cantero, Antonio da Insua, que confesó haber laborado en el convento no solo a las órdenes de Antonio Rodríguez Maseda, sino también bajo las de Francisco Rosillo $^{26}$, personaje que cabe identificar con Francisco López Rosillo, otro maestro cántabro perteneciente a la órbita de Ibáñez Pacheco y activo desde la década de 1630 en la Mariña, especialmente en el monasterio benedictino de Vilanova de Lourenzáa ${ }^{7}$.

20 Ibídem, ff. 67v-68r.

21 Archivo Municipal de Mondoñedo (A.M.M.), carp. 928, Libro de Actas (1651-1655), 1654, ff. 89v 90v, 92v, 109r, 117r.

22 Este cantero sabía firmar, A.H.P.L., P.N.M., Domingo López Traveso, leg. 6865-2, ff. 145r - 146v.

23 Ídem, leg. 6865-3, ff. 61r - 62v.

24 Juan Díaz sabía rubricar, no así Toribio, ídem, Bartolomé Díaz de Río y Aguiar, leg. 7017-6, ff. 42r 42v, 45r; ídem, Domingo López Traveso, leg. 6865-3, ff. 38r - 38v.

25 A.R.G., R.A., leg. 10124-20, ff. 9r - 10r y ss, 50r, 51v y ss, 65v y ss, 72v - 73r, 77r., 119r y ss.

26 Ibídem, ff. 99v - 100r, 101r, 102r.

27 En 1637 declaró provenir del Valle de Liendo, A.H.P.L., P.N.M., Bernabé García Cordido, leg. 8277-5, ff. 127r - 131v; P. Pérez Costanti, (1930): op. cit., pp. 341-342; A. Goy Diz, (1996): op. cit., pp. 239-241; M. Taín Guzmán, (1999): op. cit., pp. 499-504; L. Fernández Gasalla, (2004): op. cit., pp. 938-942. 
El modus operandi del taller que contribuyó a levantar el cenobio debió de tener continuidad en la arquitectura local de los años venideros, pues en septiembre de 1661 el regidor local Diego Teijeiro de Aguiar se convino con el maestro de obras Pedro Martínez Cuéllar en que le construyese la casa labrando la cantería a razón de 3 reales por vara, «mediendose conforme al estilo y se medio la que se hiço al cap ${ }^{n}$ Don $\mathrm{P}^{\circ}$ Vaamonde y Saavedra para su conbento y casa que hedifico en el dho coto de otero» ${ }^{28}$. Este dato no implica que Martínez Cuéllar hubiese trabajado en aquel pazo y cenobio, pero desde luego sí cabe la posibilidad de que lo hubieran hecho tanto él como los canteros que a sus órdenes levantarían la vivienda del munícipe.

Pese a que desde el momento de su instalación las monjas se quejaron en repetidas ocasiones de los malos materiales y la falta de diafanidad con que se habían edificado los dormitorios, entre 1683-1684 volvieron a confiar en Antonio Rodríguez Maseda para que los reformase. Así pues, lo contrataron pasadas tres décadas de su primera intervención en el convento para que por 13.000 reales hiciese catorce celdas sobre la primitiva planta baja que cerraba el flanco oriental ${ }^{29}$. En su testamento de 1689 aseguró que le debían más de 7.000 reales por estas y más obras todavía inacabadas, y que había obviado hacer otras ajustadas por la desidia del patrono, como el enjalbegado de la iglesia o la colocación de un escudo de $\operatorname{armas}^{30}$.

\section{DESCRIPCIÓN Y “RECONSTRUCCIÓN” DEL CONVENTO DESAPARECIDO}

Como queda señalado, del monasterio perdido no hemos hallado ni las trazas originales ni las condiciones de obra en base a las que se levantó. Pero sí informes periciales a los que se vio sometido entre 1707 y 1708 por arquitectos como fray Gabriel de Casas; maestros de obras como Alonso de Casal, Domingo Maceiras o Andrés González; e incluso escultores y retableros, caso de Bernabé García de Seares. Dichas inspecciones, sumadas a otros datos tan dispares como certeros, nos proporcionan una idea muy nítida de cómo sería ese cenobio original que ahora nos proponemos "reconstruir" 31 .

28 A.H.P.L., P.N.M., Alonso Rodríguez Villares, leg. 6857-3, s.f.

29 Rodríguez Maseda dispuso siete celdas a cada lado del flamante dormitorio con un pasillo en medio. El costo total de esta obra ascendió hasta los 16.250 reales, y en buena medida la financiaron las monjas con sus propias dotes, A.C.M., Misc., arm. 2, est. 1, leg. 8, n. ${ }^{\circ} 2$, s.f.; A.C.M.C.F.M., Libro de Cuentas (1660-1711), Cuentas de 1683 y 1684, s.f.; ídem, “Traslacion...”, ff. 27v, 51v, 117v, 133v - 134r. En los primeros años de la década de 1690 a Rodríguez Maseda se le abonaron 200 reales por los «bien hechos» o demasías que hizo en el dormitorio nuevo, ídem, Libro de Cuentas (1660-1711), cuentas 12/1691 11/1/1695, s.f.; ídem, "Traslacion...", f. 52r.

30 A.H.P.L., P.N.M., Luis Fernández Salgado, leg. 8269-11, ff. 43r - 44r, 46r (2a fol.). Dicha tasación ya fue indicada sin entrar en detalles por P. Pérez Costanti, (1930): op. cit., pp. 479-480. A alguna de estas obras aludió Fernández Gasalla desconociendo que hacían referencia al concierto efectuado en 1683 entre el maestro y las monjas, L. Fernández Gasalla, (2004): op. cit., p. 945.

31 La información en base a la que reconstruiremos la morfología del convento en los siguientes párrafos ha sido recogida de: A.C.M., Misc., arm. 2, est. 1, leg. 8, n. ${ }^{\circ}$ 2, s.f.; A.C.M.C.F.M., "Traslacion...", ff. 
El convento se hallaba frente al pazo de los Baamonde, hoy conocido como Pazo de San Isidro $^{32}$ (fig. 1 y 2). Esta casa solariega tenía en 1656 «quatro torres a las quatro esquinas», inscribiéndose en una de ellas el escudo de armas de los Sarmiento por pertenecer a dicho linaje la tatarabuela de Pedro Fernández Baamonde. Alrededor del inmueble había viñas de cepa y «guertas de limones naranjas limas dulçes frutales ortaliças y mas arboles» cerradas con su correspondiente cerca $^{33}$.

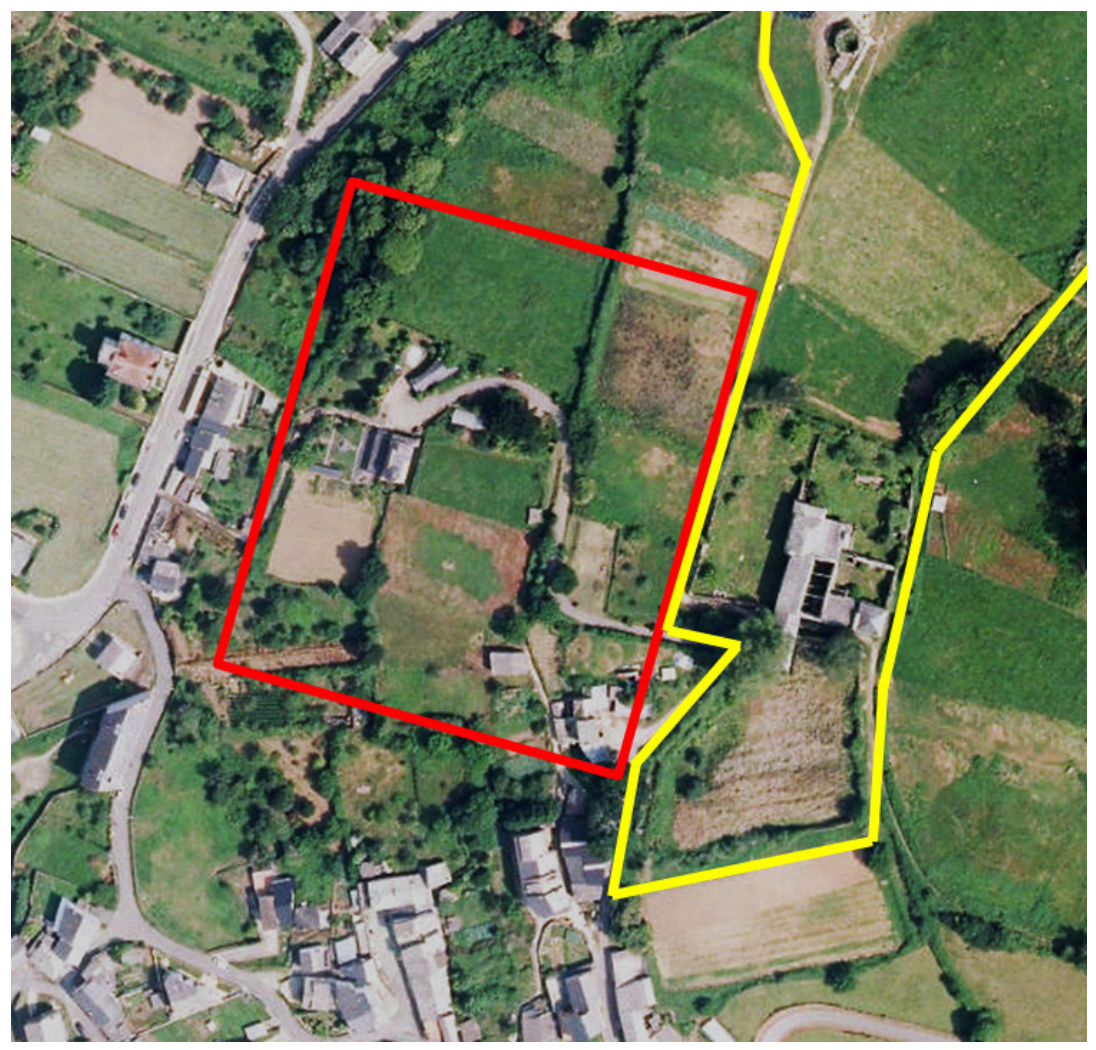

Figura 1. Infografía del autor sobre vista aérea tomada de http://mapas.xunta.gal/visores/descargas/ cuya sección amarilla indica los límites de propiedad del Pazo de San Isidro. La roja, por su parte, el espacio donde se ubicaría el desaparecido convento de la Encarnación.

$115 \mathrm{v}-116 \mathrm{r}, 131 \mathrm{r}-132 \mathrm{v}, 241 \mathrm{v}-242 \mathrm{v}, 257 \mathrm{v}-260 \mathrm{v}$; A.R.G., R.A., leg. 10124-20, fols. 1r, 4v, 5r, 11r $-11 \mathrm{v}, 13 \mathrm{v}, 17 \mathrm{r}-17 \mathrm{v}, 21 \mathrm{v}, 44 \mathrm{v}, 52 \mathrm{r}-52 \mathrm{v}, 60 \mathrm{r}, 81 \mathrm{r}, 88 \mathrm{v}, 179 \mathrm{r}$; A.H.P.L., P.N.M., Salvador Rodríguez de Ponte, leg. 6303-2, f. 21v. Parte de ella también la transcribió S. San Cristóbal, (2001): op. cit., pp. 42-43, 49-52.

32 El 12 de abril de 2018 la Xunta de Galicia lo declaró Bien de Intéres Cultural. Quiero expresar mi agradecimiento a sus dueños, el matrimonio formado por José Jaime de Orozco Sánchez-Aguilera y Simonetta Dondi dall'Orologio por su amabilidad a la hora de permitirme el acceso a la propiedad. A.H.P.L., P.N.M., Antonio Fernández Cedofeita, leg. 7166-1, ff. 38v - 39r. 


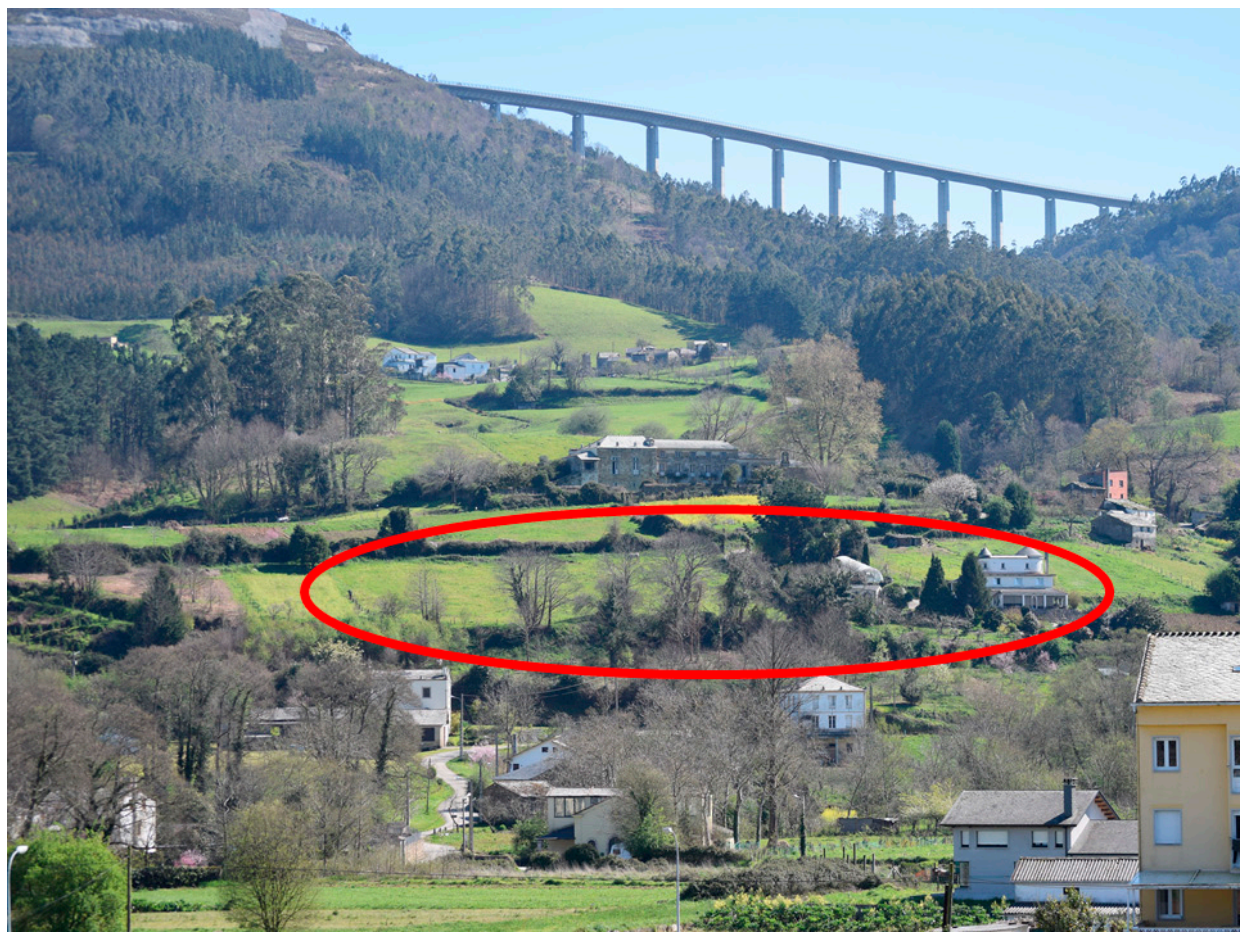

Figura 2. Infografía del autor cuyo óvalo rojo señala la falda del promontorio sobre el que se erigía el extinto convento de la Encarnación de Mondoñedo (fotografía del autor).

La planta del cenobio era cuadrangular. Radicaba frente al pazo, en un terreno en pendiente, de tal forma que su lado occidental se hallaba en una cota inferior al opuesto. En el flanco septentrional del conjunto se ubicaba la iglesia, cuya cabecera se orientaba hacia el este. El templo se erguía en un nivel inferior respecto al resto del convento por enclavarse en «la caida o desfiladero de un monte». Tenía planta de cajón y medía aproximadamente 36 metros de largo por 8 de ancho. La nave se cubría con una bóveda de cañón de seis tramos cuyos arcos fajones no alcanzaban a dibujar un medio punto perfecto. A esta seguía un crucero con una media naranja o en todo caso una bóveda vaída, y a continuación un último tramo abovedado correspondiente a la capilla mayor. Los muros interiores carecían de cualquier elemento articulador y/o sustentante, de tal forma que las arcuaciones de la bóveda descargaban sobre unas ménsulas de cantería unidas por una imposta. Únicamente había pilastras dentro del tramo correspondiente al crucero; concretamente cuatro, y sobre estas se armaban otros tantos arcos torales que sustentaban la media naranja. A los pies de la iglesia se hallaban los coros bajo y alto, y en el muro septentrional se abría la portada, que tenía sobre sí un vano.

El claustro se encontraba anejo al muro meridional del templo. Su planta era cuadrangular y medía aproximadamente 26,5 metros de largo por sus lados norte y sur mien- 
tras que 29 en los restantes. Las pandas contaban con una anchura de 2,5 metros y en cada una se abrían siete arcos que daban al jardín central ${ }^{34}$. La techumbre de las crujías era de madera y la totalidad de las paredes de pizarra. Alrededor del patio se repartían los dormitorios y oficinas. El flanco occidental lo cerraba la fachada que miraba a la ciudad, de ahí que contase con la portería. También albergaba el refectorio y la zona de acceso al coro bajo de la iglesia. El frente meridional decía a las huertas de las religiosas. Sus muros acogían un cuarto común, la cocina, la antecocina y la leñera. Por su parte, el cierre oriental se hallaba en la zona más alta del convento, existiendo a continuación un terraplén y las huertas de los Baamonde. En la planta baja, por el ángulo suroriental, se abría un pasillo que venía del claustro y salía hacia la referida huerta conventual bajo un arco. A continuación se encontraban la bodega, la sacristía, y por último la cabecera del templo. Sobre dicha planta baja montaba el llamado «quarto nuevo», es decir, las celdas realizadas por Rodríguez Maseda en la década de 1680 y una pieza común con chimenea. A espaldas de la capilla mayor también había un locutorio, y sobre este un mirador protegido por una reja lignaria al que salían las monjas a «esparcir la bista» hacia la propiedad de los patronos, estancia de la que ofreceremos más detalles en los dos siguientes párrafos. Finalmente, como se dijo, el flanco norte del conjunto lo ocupaba el cierre lateral del templo en el que se abría su portada.

De la zona oriental del convento contamos con mayores datos gracias a que en noviembre de 1669 se giró una visita pastoral que dictaminó que su clausura era demasiado laxa, que carecía del debido mobiliario, y que su fábrica arquitectónica parecía muy defectuosa, encontrándose el cenobio «descompuesto y desmantelado sin mas abrigo que unas imperfectas paredes». Por si fuera poco se creía que el patrono Isidro Alonso Baamonde retenía parte del caudal que anualmente debía otorgar a las monjas ${ }^{35}$. Para colmo existían pruebas de que el aludido locutorio oriental, edificado con la finalidad de que la madre abadesa pudiese tratar asuntos con ciertos particulares o dar las cuentas de la fábrica al provisor sin el «bullicio» de la portería y locutorio occidentales ${ }^{36}$, lo empleaba el patrono a su antojo como si fuese una prolongación del pazo que tenía enfrente. Al parecer poseía la llave del mismo, y después de franquear la puerta de la cerca conventual, entraba allí cuando le venía en gana «acompañado de mucha gente moça a todas oras de dia y de noche [...] ablando con las religiosas de su devoçion, donde continuaban saraos, musicas,

34 Por las dimensiones y número de arcos del claustro, creemos que la morfología de sus pandas sería muy similar a la de los claustros vivarienses del desaparecido convento de Santo Domingo y al de San Francisco, ambos obra de Diego Ibáñez. Así, las crujías se conformarían mediante unas arquerías de medio punto aupadas en pilastras. También se asemejaría al claustro del monasterio vivariense de Valdeflores, realizado por Pedro Martínez Cuéllar a finales del siglo XVII siguiendo el modelo del citado claustro dominico. Sobre esta cuestión véase A. Goy Diz, (1996): op. cit., pp. 226, 228-235. Al parecer, este último reiteraba el diseño del claustro del convento dominico de A Coruña, erigido por un maestro desconocido en las dos primeras décadas del seiscientos, L. Fernández Gasalla, (2004): op. cit., pp., 1027-1028.

35 A.R.G., R.A., leg. 10124-20, ff. 1v, 4v, 148r - 148v, 166r, 177r.

36 A.H.P.L., P.N.M., Antonio Fernández Cedofeita, leg. 7167-5, ff. 97r - 97v. 
zenas, y banquetes en relaxaçion manifiesta de la vida monástica». Varios testigos dieron crédito a esta acusación y verificaron que allí se comía y se dormía la siesta, y de todo lo que el patrono y sus amigos «obraban en dho locutorio abia escandalo, y mormuraçion liuelos, y coplones publicos» que corrían por Mondoñedo. A fin de evitar esta vergonzosa situación el obispo Luis Tello de Olivares mandó prender a Isidro Alonso Baamonde y tapiar la entrada al locutorio y a otros espacios del templo que ahora describiremos ${ }^{37}$.

El citado locutorio se situaba en el ángulo noreste del testero de la capilla mayor, frente al pazo. Tenía una puerta de cantería adintelada y enrejada con hierro; y en su interior un torno y una reja de madera que distaba de la puerta apenas una vara. Sobre este espacio se aupaba un mirador que daba a la huerta y casa de los Baamonde, al que, como se dijo, salían las religiosas a «esparcir la bista». Al locutorio tenían acceso el patrono y su familia. Lo frecuentaban con el pretexto de que eran familiares y parientes de varias profesas. Además desde dicha estancia contaban con el privilegio de acceder directamente al templo y oír la misa desde una tribuna que colgaba sobre el lado del Evangelio de la capilla mayor. Esta era de madera con su correspondiente barandilla y ostentaba una longitud próxima a cuatro varas, o sea, casi la mitad de la anchura de la capilla. En altura no alcanzaba ni tres varas. Estas dimensiones las creyó absolutamente indecentes el obispo y alegó que el patrono y sus familiares «si escupian, o echaban tierra era preçiso cayese sobre dho sacerdote». También adujo que dada su escasa elevación no les resultaría complicado saltar hasta la iglesia y alcanzar a las monjas, pues carecían de la debida reja en el coro bajo. En definitiva, estos argumentos, sumados a los que ya conocemos, derivaron en la orden episcopal de tapiar la puerta de la tribuna y deshacer esta ${ }^{38}$.

\section{DE 1658 A 1708: VIVIENDO MEDIO SIGLO BAJO UNA RUINA ARQUITECTÓNICA}

El monasterio de la Encarnación cuenta con varias características equiparables a otros muchos conventos concepcionistas de la España de entonces, inclusive al cercano de Viveiro fundado a inicios del XVII. Constituían cenobios femeninos erigidos en pequeñas poblaciones con el patrocinio de una nobleza también pequeña que a duras penas

37 También justificó su acción expresando que la situación del locutorio ponía en peligro la vida de las monjas por ubicarse junto a un bosquecillo frondoso, A.R.G., R.A., leg. 10124-20, ff. 1r - 1v, 3r, 4r - 4v, $5 \mathrm{r}-5 \mathrm{v}, 21 \mathrm{v}, 81 \mathrm{r}, 82 \mathrm{r}, 152 \mathrm{r}$.

38 Ibídem, ff. 1r - 1v, 3r, 4r - 4v, 5r, 11r - 11v, 17v, 21v, 44v, 52r - 52v, 59v, 68r, 73r, 74v - 75r. De cegar las puertas del locutorio en 1670 y de echar abajo la tribuna se encargaron distintos canteros y carpinteros. Varios de ellos habían contribuido a levantar el convento años antes. Incluso alguno reveló la edad que tenía en el presente. Así, Antonio da Insua declaró contar con 68 años; el carpintero Andrés Pardo de Paz con 60; mientras que los pedreros Pedro García, Juan González de Orense y Bartolomé Valiño dijeron rondar los 40. A mayores hubo otros canteros cuya edad no se reseña, caso de Antonio García da Arqueira, Alonso López de Noche o Juan Ramos, ibídem, ff. 9r - 10v, 12r y ss, 16r y ss, 18r y ss, 50r y ss, 65v y ss, 72v, 77r, 86v, 87v, 99v - 100r, 101r, 102r, 119r y ss. 
conseguía financiar la fundación, pero que se esforzaba por mantener el patronato de la comunidad e incluir dentro de ella a familiares ${ }^{39}$. Y efectivamente, nada más concluirse las obras en 1658 ingresaron allí las cuatro primeras franciscanas procedentes de Viveiro. Desde el momento de su instalación pudieron comprobar que su nueva casa radicaba en un lugar especialmente frío y húmedo, que el resultado de su construcción no hacía prever mucha seguridad, y que el patrono no había cumplido con todo lo dictaminado por la fundadora, pues no se habían hecho las treinta celdas para otras tantas religiosas y el templo carecía de retablos, órgano, rejas, sillerías de coro, libros de canto, alhajas litúrgicas y otros enseres necesarios para el culto ${ }^{40}$.

Disconformes con la situación, en diciembre de 1670 advirtieron que levantarían un pleito a los Baamonde por ignorar su petición de financiar los retablos. También solicitaron más celdas y la reparación de los corredores y locutorios dado su mal estado. El patrono se defendió diciéndoles que sí que contaban con treinta celdas y que el refectorio y su mobiliario se encontraban perfectamente, entre otras cosas porque antes de que la comunidad se instalase en el convento -e incluso en el día en que el Santísimo se trasladó desde la catedral- allí había almorzado en distintas ocasiones el obispo Francisco de Torres junto con canónigos, familiares y demás caballeros locales. Las monjas le respondieron que preferían poner sus «dudas y pretensiones» en manos del provisor y vicario general de la diócesis a pleitear, así que Isidro hizo lo propio y tomó por abogado a un regidor de la ciudad ${ }^{41}$

Finalmente, en abril de 1674, el provisor, acompañado de dos canónigos y del fiscal eclesiástico del obispado, acudió hasta el Couto de Outeiro a visitar el convento. Vieron la iglesia y manifestaron que las monjas tenían razón, pues carecía de retablos y urgía reparar las grietas de la bóveda del sotacoro. Las demás piezas conventuales las hallaron por lo general en muy mala situación, pues aparte de estar pésimamente ejecutadas llovía en su interior, existiendo «rriesgo de que en mui poco tiempo se caiga todo en el suelo». Comprobaron que había celdas en las que vivían dos monjas juntas por resultar algunas inhabitables, y que otras estancias, inclusive el coro bajo del templo, presentaban un suelo sin entarimar ni enlosar ${ }^{42}$.

Esta paupérrima situación se fue solucionando paulatinamente. Como hemos visto con anterioridad, entre 1683-1684 Antonio Rodríguez Maseda construyó nuevas celdas

39 J. García Oro, (2001): op. cit., pp. 50-51.

40 A.C.M., Misc., arm. 2, est. 1, leg. 8, n. ${ }^{2}$, s.f.; A.C.M.C.F.M., "Traslacion...”, f. 27r; C. Adrán Goás, (2001): «Abadologio», in S. L., Pérez López (coord.), El Monasterio de la Concepción, Viveiro, pp. 269270. El propio Pedro Fernández Baamonde reconoció en su testamento de 1664 que no había llevado a cabo el retablo mayor, A.H.P.L., P.N.M., Antonio Fernández Cedofeita, leg. 7166-8, ff. 35r - 44v.

41 A.H.P.L., P.N.M., Antonio Fernández Cedofeita, leg. 7167-5, ff. 95v - 97r, 99r; E. Lence-Santar (1910): op. cit., p. 6.

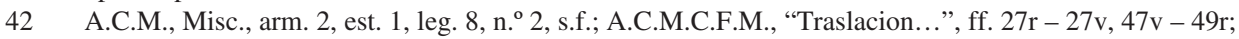
A.C.M.C.F.M., carpeta sin signatura, documentación suelta, s.f. S. San Cristóbal, (2001): op. cit., pp. 42-43. 
sobre el antiguo dormitorio del flanco oriental. También se hicieron distintas mejoras en el mobiliario, siendo la más destacada la ejecución del retablo mayor, que cubrió por completo el testero de la capilla mayor. La suma de estas y otras obras importó una cifra aproximada de 40.000 reales $^{43}$. Más de un tercio de esta cantidad se destinó al retablo, ejecutado por el escultor Bernabé García de Seares a partir de 1693 en base a una segunda traza suya, luego de que el patrono decidiese detener la obra de otro ya iniciado y diseñado por el propio maestro ${ }^{44}$.

No obstante los problemas tectónicos no desaparecieron con estas obras y durante el último cuarto del siglo XVII hubo que arreglar en distintas ocasiones la bóveda del templo, el claustro, u otras partes del cenobio que dieron buen ejemplo de la escasa firmitas con que se había levantado ${ }^{45}$. En febrero de 1707, a petición de la madre superiora, el maestro de obras coruñés Domingo Maceiras y el referido Bernabé García de Seares reconocieron su lamentable situación ${ }^{46}$. Como consecuencia de su análisis el obispo fray Juan Muñoz destinó de inmediato 2.000 reales para reparar algunas celdas y conformar un oratorio seguro en la sacristía a fin de que las monjas no tuviesen que acceder a la iglesia a celebrar los oficios litúrgicos ${ }^{47}$. Y el 15 de septiembre él mismo acudió al convento para comprobar el estado en que se hallaba. Lo hizo acompañado de varios miembros de su Iglesia, así como del maestro de obras lucense Alonso de Casal y del carpintero local Alonso López de Cora ${ }^{48}$.

Los peritos determinaron que la bóveda de la nave tenía importantes grietas, acusándose las de mayor gravedad sobre el coro alto. A su juicio esto venía provocado porque las paredes del templo carecían del grosor debido y porque no existía ningún ele-

43 A.C.M., Misc., arm. 2, est. 1, leg. 8, n. ${ }^{\text {2 }}$, s.f.; A.C.M.C.F.M., “Traslacion...”, f. 27v; S. San Cristóbal, (2001): op. cit., p. 43

44 A.H.P.L., P.N.M., Francisco Tubia y Castro, leg. 5571-1, ff. 73r - 74v; ídem, leg. 5571-2, s.f.; ídem, leg. 5571-8, s.f.; A.C.M.C.F.M., Libro de Cuentas (1660-1711), cuentas 12/1691 - 11/1/1695 y cuentas de 1695 y 1696, s.f.; ídem, “Traslacion del Convento á Mondoñedo 1.700 á 1.708”, ff. 52r - 52v. Parte de esta documentación ya ha sido aportada por P. Pérez Costanti, (1930): op. cit., pp. 236-237; M. Taín Guzmán, (1999): op. cit., pp. 478-479; L. Fernández Gasalla, (2009-2011): «O escultor e mestre de arquitectura Bernabé García de Seares (1670-1714)», Boletín do Museo Provincial de Lugo, 14, pp. 36-37; Ídem, (2009-2011): «Documentos sobre o mestre de arquitectura e escultura Bernabé García de Seares no Arquivo Histórico Provincial de Lugo (1681-1696)», Boletín do Museo Provincial de Lugo, 14, pp. 54-60. Dicho retablo es el que hoy ocupa la capilla mayor del actual convento de la Encarnación de Mondoñedo.

45 Entre 1679-1681 hubo que reparar la bóveda; en 1687 y a inicios del XVIII el claustro; y en 1688 se desmoronó parte de la cerca, volviendo a ocurrir lo mismo en los primeros años del setecientos, A.C.M.C.F.M., Libro de Cuentas (1660-1711), cuentas de 1679, 1681, 1687, 1688, s.f. y también las comprendidas entre 4/2/1701 - 6/5/1704 y 6/5/1704 - 6/5/1707, s.f.; S. San Cristóbal, (2001): op. cit., pp. $40-41$

46 A.C.M., Misc., arm. 2, est. 1, leg. 8, n. ${ }^{2}$ 2, s.f.; A.C.M.C.F.M., “Traslacion...”, ff. 151r - 152r.

47 Esto se efectuó o bien en el primer semestre de 1707 o en todo caso a mediados de dicho año, A.C.M., Misc., arm. 2, est. 1, leg. 8, n. ${ }^{\circ}$ 1, f. 27 r, e ídem, n. ${ }^{\circ}$ 2, s.f.; A.C.M.C.F.M., Libro de Cuentas (1660-1711), cuentas 6/5/1707 -6/3/1710, s.f.

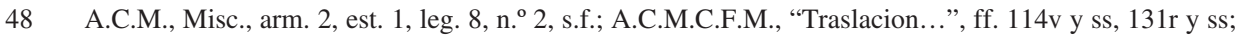
S. San Cristóbal, (2001): op. cit., pp. 44-45. 
mento sustentante bajo las impostas sobre las que cargaba la bóveda, como tampoco contrafuertes en el exterior en correspondencia con los arcos. Por si fuera poco pudieron comprobar que tanto los muros como las arcuaciones se habían realizado con mampostería y pizarra, empleándose únicamente la cantería en las pilastras sobre las que se aupaba la media naranja.

Respecto a las demás dependencias hallaron en un pésimo estado la techumbre lignaria del claustro y las escaleras de acceso a los dormitorios. Las fachadas que cerraban su perímetro exhibían asimismo un aspecto lastimoso, apreciándose distintas brechas a lo largo y ancho de sus muros, así como en sus linteles, capialzados, etc. La pared oriental que cerraba el altar mayor y daba a la huerta de los patronos tenía más de la mitad de su altura hundida bajo tierra. Con lo cual absorbía toda la humedad proveniente del monte inmediato, y esto se agravaba cada vez que llovía, ocasionando un daño terrible a la madera del retablo. En fin, Casal y López de Cora declararon que lo más conveniente sería hacer el convento de nuevo, lo que supondría un costo de 90.000 reales.

Acabada la inspección fray Juan Muñoz ordenó cimbrar las bóvedas del templo, postearlo, y hacer lo propio con las demás paredes del convento que lo necesitaren. Concluyó en base al informe que solo algunas celdas y la portería presentaban un estado salvable dentro de la ruina general del complejo. Consecuentemente las franciscanas se fueron a vivir al dormitorio especificado y el monasterio se apuntaló siguiendo las directrices de Alonso de Casal, quien acudió en dos ocasiones desde Lugo para comprobar los resultados ${ }^{49}$. Poco después el obispo confió a Bernabé García de Seares que analizase si el apuntalamiento se había realizado de manera eficiente. El escultor cumplió su cometido y se personó en el convento los días 24 y 25 de noviembre de 1707, aunque «se excuso umildemente declarando ser de poca inteligenzia en el arte» de la arquitectura. De todos modos el prelado consideraba que «en esta Çiu ${ }^{\mathrm{d}}$ ni al contorno» había peritos que ejerciesen como tal, y a sabiendas de que sus convecinos tenían a Bernabé por un «Maestro que es de los mas afamados" por ser "el mexor q oi se alla en esta ziud», decidió que fuese él quien llevase a cabo este trámite. Eso sí, el obispo «rezeló de entrar adentro temiendose del peligro de la uida» y permaneció en la portería. Sí acompañaron al tallista varios canónigos y otros clérigos junto con regidores y autoridades locales, a buen seguro preocupadísimos por el estado del convento puesto que tenían familiares viviendo en su clausura $^{50}$.

Bernabé describió una vez más un panorama desolador. Expresó que el conjunto mostraba peor aspecto que cuando lo había visitado ocho meses atrás y que corría serio

49 A.C.M., Misc., arm. 2, est. 1, leg. 8, n. ${ }^{\circ}$ 1, ff. 33v - 34r; ídem, n. ' 2, s.f.; A.C.M.C.F.M., "Traslacion...", ff. 115v - 117r, 118r, 131v - 133r, 134r, 140r; ídem, Libro de Cuentas (1660-1711), cuentas 6/5/1707 6/3/1710, s.f.

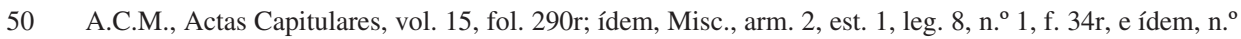
2, s.f.; A.C.M.C.F.M., “Traslacion...”, ff. 140r y ss. Bernabé cobró 39 reales y 14 maravedíes por llevar a cabo la inspección, ídem, Libro de Cuentas (1660-1711), cuentas 6/5/1707 - 6/3/1710, s.f. 
riesgo de venirse abajo, de ahí que la vida de las concepcionistas peligrase. Estas vivían confinadas bajo unas techumbres cuyo paupérrimo maderaje cedía hasta el punto de formar «ovalos»; e igualmente entre paredes posteadas, agrietadas, inclinadas, y con «barriga» en el mejor de los casos -cuando no parcialmente desmoronadas-. Reiteró que una pésima cimentación, así como una ejecución en piedra de mala calidad y barro, en lugar de cantería y argamasa, constituían las principales causas de que el estado del complejo fuese tan desastroso ${ }^{51}$.

Viendo semejantes informes periciales se comprende que las monjas rogasen al prelado entre «lagrimas» que les diese alojamiento en un sitio seguro y salubre ${ }^{52}$. Y máxime luego de que el vicario general de la diócesis, tras ver el dormitorio conventual, declarase que el «calavoço» de la «carzel de Corona» de Mondoñedo era «pieça mas dezente mas segura y mas avitable que la mexor çelda» del cenobio ${ }^{53}$. Sin más preámbulos, ese 25 de noviembre el mitrado indicó que existían dos opciones como residencia alternativa: o el Colegio Seminario o su palacio episcopal. La primera acarrearía hospedar a los muchachos por distintas casas de la ciudad. El Cabildo la votó y no prosperó por 15 votos frente a 12. Entre medias la madre del patrono propuso dar cobijo a las monjas en su propia morada, pero tampoco se consideró viable. Así que al día siguiente fray Juan Muñoz comunicó al provisor que este y su familia debían de desocupar sus aposentos de palacio porque pronto tendrían nuevas inquilinas. Y efectivamente, en las primeras horas de la tarde del 30 de noviembre, el obispo se personó en la portería conventual para buscar a las franciscanas y conducirlas hasta las casas episcopales. Aunque todo sea dicho alguna se resistió a mudarse. Manifestó que vivirían allí de forma provisional durante seis meses e instó al patrono a que durante dicho periodo convirtiese el convento en un lugar mínimamente habitable ${ }^{54}$.

Escasas semanas después de la marcha de las monjas la iglesia se siguió empleando para algún que otro oficio religioso. Y en una ocasión, en plena celebración, se desprendieron varias piedras de la bóveda. Ante la pasividad e ineficiencia que mostraban los tutores del patrono Isidro José Baamonde y Figueroa, surgió un pleito entre estos y el obispo a inicios de 1708. El mitrado alegaba que debían reedificarlo y dar cobijo a las religiosas, mientras que los curadores defendían que el arreglo del inmueble competía a las monjas y que estas percibían rentas suficientes como para financiarlo. Argumentaban además que el edificio era seguro y habitable, sobre todo en lo que respecta a las catorce celdas levantadas por Rodríguez Maseda en la década de 1680, y que las profesas debían de regresar allí cuanto antes, pues no consideraban justo que lo hubieran abandonado en

51 A.C.M., Misc., arm. 2, est. 1, leg. 8, n. ${ }^{\circ}$ 1, ff. 33v - 34r; A.C.M.C.F.M., “Traslacion...”, ff. 114v y ss, 131r y ss, 151r - 152r; S. San Cristóbal, (2001): op. cit., pp. 46-47.

52 A.C.M., Misc., arm. 2, est. 1, leg. 8, n. ${ }^{\circ}$ 2, s.f.; A.C.M.C.F.M., "Traslacion...”, ff. 140r - 151r.

53 A.C.M.C.F.M., "Traslacion...", ff. 159r - 159v.

54 A.C.M., Actas Capitulares, vol. 15, ff. 291r - 291v; ídem, Misc., arm. 2, est. 1, leg. 8, n. o 1, f. 2v, e ídem, n. ${ }^{\circ}$ 2, s.f.; A.H.P.L., P.N.M., Antonio Fernández de Parga, leg. 7333-1, f. 101r; E. Lence-Santar, (1910): op. cit., p. 6; S. San Cristóbal, (2001): op. cit., p. 48; E. Cal Pardo, (2003): op. cit., pp. 679-680. 
base al peritaje de Bernabé García de Seares cuando este no era «maestro de canteria, ni piçarra, ni jamas uso ni exerçio tal ofizio», algo que había quedado de manifiesto en su informe y que además el propio escultor había reconocido. Igualmente consideraban que Alonso de Casal tampoco era «maestro yntelixente» para examinar nada, y que a ellos no se les había dado la oportunidad de contratar a alguien que inspeccionase el estado del edificio $^{55}$.

Con lo cual, a mediados de marzo trajeron desde A Coruña a los maestros de obras Domingo Maceiras, a quien tenían por «uno de los de primer nombre deste rreino» y que dijo contar con 53 años, y a Andrés González, quien aseguró tener unos 62 aproximadamente. De esta manera obviaron a otros colegas como los mencionados Bernabé García de Seares o Alonso de Casal, y también a Miguel Rico de Sacido, José de Lepina, Antonio Fernández Villanueva, o Diego Gil de Coto, por considerarlos «vassallos» del obispo. Ambos maestros coruñeses hicieron el reconocimiento pericial junto con dos carpinte$\operatorname{ros}^{56}$. Poco aportaron que no sepamos ya. Reiteraron que la iglesia se había levantado sobre un terreno excesivamente húmedo y que para colmo se había cimentado de manera irrisoria, hallándose además buena parte de la cabecera enterrada en el monte o terraplén contiguo. Que su fábrica se había hecho con barro en vez de cal y arena, y que casi todo era de pizarra. También apreciaron lo torcidas y rotas que estaban sus paredes, carentes por supuesto de contrafuerte alguno; o que las bóvedas no se habían ejecutado siguiendo un medio punto canónico. El resto de las dependencias las hallaron igualmente en muy mala situación, inclusive la zona del dormitorio levantada por Rodríguez Maseda treinta y cinco años atrás. En líneas generales manifestaron que la fábrica de piedra del edificio se había hecho deficientemente en cuanto a modo y materiales. La de carpintería, por su parte, no era mala en su ejecución, pero sí en la calidad de la madera. Así que aconsejaron demoler todo y hacerlo ex novo desde los cimientos. En base a su tasación la obra de cantería supondría una inversión de 132.000 reales, mientras que la lignaria de $48.000^{57}$. Acabado el análisis el patrono dio muestras de una sorprendente tozudez declarando que ni Andrés González ni uno de los carpinteros que habían supervisado el edificio eran personas cualificadas para ello ${ }^{58}$.

Pero las sorpresas a la hora de desacreditar a ciertos profesionales no quedaron ahí. Pues sabiendo el obispo que por aquellas fechas el arquitecto fray Gabriel de Casas se encontraba en la villa de Vilanova de Lourenzá, requirió de sus servicios para que hiciese la inspección del convento. Muñoz y Salcedo tenía a este monje, de 52 años y

55 A.C.M., Misc., arm. 2, est. 1, leg. 8, n. ${ }^{\circ} 2$, s.f.

56 A.C.M.C.F.M., "Traslacion...”, ff. 234r - 239r. Domingo Maceiras y Andrés González se movieron entre A Coruña y Mondoñedo con caballos de alquiler. Durante su estancia en la ciudad episcopal se hospedaron «en el messon, y casa de Alondiga, q està en la plaza pp. ca desta Ciud», A.C.M., Misc., arm. 2 , est. 1 , leg. 8, n. $^{\circ} 2$, s.f.

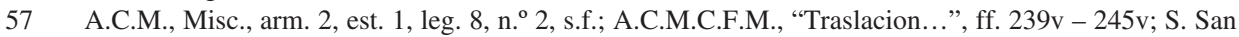
Cristóbal, (2001): op. cit., pp. 49-52.

58 A.C.M., Misc., arm. 2, est. 1, leg. 8, n. ${ }^{\circ}$ 2, s.f. 
profeso en San Martín Pinario, por un «maestro de los de primer crédito en Arquitectura, y otras artes». Sin embargo, el patrono tuvo el arrojo de negar la validez de su informe argumentando que ni era arquitecto ni le conocía. Para la madre abadesa el benedictino sí era un «Maestro de los primeros del Reyno en el arte de arquitectura y assi corre de pubca voz, y fama». Finalmente, el 24 de marzo de 1708 hizo el reconocimiento pericial, acudiendo dos días después al palacio episcopal para dar a conocer los resultados de su análisis ${ }^{59}$.

Fray Gabriel elaboró un informe más preciso y detallado que el de sus antecesores, empleando un lenguaje técnico y unos recursos acordes a su condición de arquitecto. Eso sí, respecto al estado de la casa monástica incidió en lo mismo en lo que habían hecho hincapié sus colegas, asegurando que se había levantado sobre un terreno de rico nivel freático y mal cimentado, con materiales pobres, muros de escaso grosor, y una endeble sustentación acorde al peso de la bóveda. Aun así expresó que ni aunque la iglesia se hubiera hecho con los mejores materiales resistiría en pie por la falta de proporcionalidad con la que se había llevado a cabo. A diferencia de los demás maestros fray Gabriel se preocupó por la salubridad del agua que llegaba al convento y dispuso cubrir el caño. También fue el único que dictaminó alzar el murallón que rodeaba el complejo. Concluyó diciendo que el mejor remedio para que las monjas gozasen de una próspera vida en el Couto de Outeiro no era otro que derruir toda la vieja fábrica y hacerla de nuevo, tasando el coste de la iglesia y demás dependencias, así como el encañado y muralla en 210.000 reales $^{60}$.

\section{LA DESAPARICIÓN DEL CONVENTO}

Finalmente en mayo de 1712 una devota residente en León llamada María Marquesa Pardo aforó a las monjas unos solares que tenía en el núcleo urbano de Mondoñedo y les dio libertad para que edificasen allí cuanto quisiesen ${ }^{61}$. El 16 de septiembre estas rubricaron con los Baamonde las condiciones de la mudanza. Las religiosas podrían reaprovechar los materiales de sus antiguas dependencias en el Couto de Outeiro salvo en lo tocante a la iglesia, de la cual solo tendrían derecho a la sección concerniente al último arco toral y a la inmediata capilla mayor, quedando para el patrono el resto de la nave y la media naranja. Los materiales se carretearían desde la falda de aquella colina hasta la urbe, donde se pondrían a pie de obra. En total serían 600 carros de bueyes pagados íntegramente por Isidro Baamonde a fin de perpetuar la vinculación de su linaje con el patronato de la casa monástica. Realmente el desmantelamiento del viejo cenobio y

59 A.C.M., Misc., arm. 2, est. 1, leg. 8, n. ${ }^{2}$ 2, s.f.; A.C.M.C.F.M., "Traslacion...”, ff. 254r - 262v.

60 A.C.M., Misc., arm. 2, est. 1, leg. 8, n. ${ }^{\circ}$ 2, s.f.; A.C.M.C.F.M., "Traslacion...”, ff. 257v - 262r; S. San Cristóbal, (2001): op. cit., p. 49.

61 A.H.P.L., P.N.M., Salvador Rodríguez de Ponte, leg. 6303-2, ff. 16r - 18r, 19r, 21v - 25r; A.C.M., Actas Capitulares, vol. 15, ff. 467r, 478v - 479r. 
la conducción de despojos ya se había iniciado hacia 1710-1711, pero el grueso de la demolición se llevó a cabo a lo largo del segundo semestre de 1712 una vez se firmaron las aludidas escrituras. En mayo del año siguiente las monjas ya habían derribado todo cuanto necesitaban, y creían que los «maestros del arte» que edificarían su nuevo convento lo harían «mas breue, façil» y con menor coste que el antiguo. De este modo pusieron punto y final a su historia sobre el promontorio del Couto de Outeiro tras seis décadas verdaderamente azarosas $^{62}$.

El nuevo monasterio se construyó entre 1713 y $1717^{63}$. Muy probablemente siguiendo unos planos del arquitecto José Martínez Celiz ${ }^{64}$. Poco se conserva en él del desaparecido, a excepción del retablo mayor, algunos blasones, los arcosolios del altar mayor, y muy posiblemente la Inmaculada que preside la portada del templo, que de forma esquemática sigue el tipo tan codificado a inicios del siglo XVII por el escultor Gregorio Fernández (fig. 3).

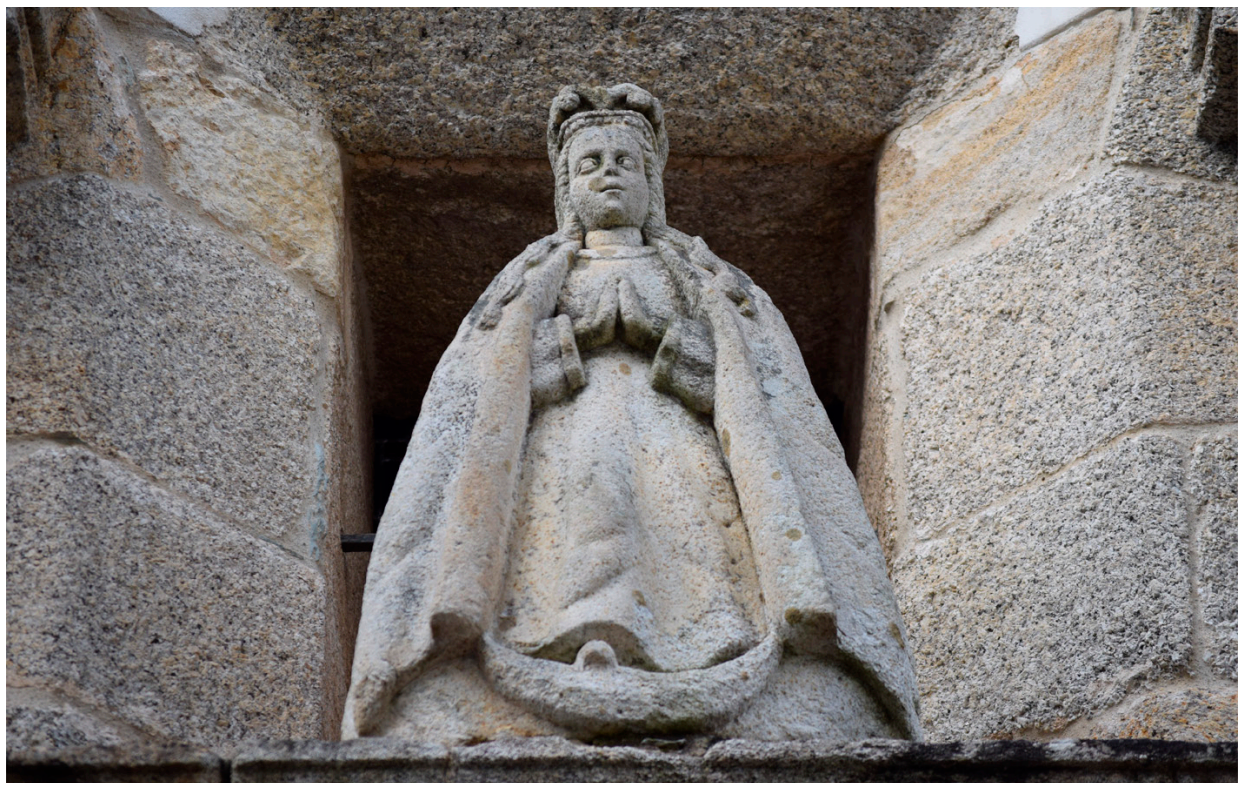

Figura 3. Imagen de la Inmaculada que preside la actual portada del convento mindoniense de la Encarnación, y que muy probablemente proviene del cenobio desaparecido (fotografía del autor).

62 A.H.P.L., P.N.M., Juan Antonio de Villar y Rubiños, leg. 7382-1, ff. 4r - 13r; ídem, Agustín de Rega y Peña, leg. 8265-1, ff. 10r - 13v; A.C.M., Actas Capitulares, vol. 15, ff. 476v - 477r, 478v - 479r; A.C.M.C.F.M., Libro de Cuentas (1660-1711), cuentas 6/3/1710 - 6/3/1711, s.f.; ídem, carpeta sin signatura, documentación suelta, s.f.; E. Lence-Santar, (1910): op. cit., pp. 7-8.

63 A.H.P.L., P.N.M., Juan Antonio de Villar y Rubiños, leg. 7382-1, ff. 95v - 105v; E. Lence-Santar, (1910): pp. 11-12.

64 A.M.M., carp. 941, Libro de Actas (1711-1715), 1713, s.f.; A.C.M.C.F.M., Libro de Cuentas (17131761), cuentas 9/3/1713-9/3/1716, s.f. 


\section{BIBLIOGRAFÍA}

Adrán Goás, C. (2001): «Abadologio», in S. L., Pérez López (coord.), El Monasterio de la Concepción, Viveiro, pp. 255-311.

Adrán Goás, C. (2014): «Regidores del Concejo de Viveiro (siglos XV al XIX)», Estudios Mindonienses, 30, pp. 267-390.

Adrán Goás, C., Pardo de Cela, S. F. (2001): «La fundación del monasterio de la Inmaculada Concepción Francisca de Viveiro», in S. L. Pérez López (coord.), El Monasterio de la Concepción, Viveiro, pp. 53-155 (existe copia de este trabajo en Estudios Mindonienses, 17).

Atienza López, A. (2008): Tiempos de conventos. Una historia social de las fundaciones en la España moderna, Madrid.

Bonet Correa, A. (1966): La arquitectura en Galicia durante el siglo XVII, Madrid.

Cal Pardo, E. (2003): Episcopologio mindoniense, Santiago de Compostela, MondoñedoFerrol.

Castro, M. de (1991): «Los monasterios de concepcionistas franciscanas en España», Archivo Ibero-Americano, 203-204, pp. 411-477.

Castro, M. de (1995): «¿Por qué el monasterio de las concepcionistas de Mondoñedo no se construyó en Pontedeume?», Estudios Mindonienses, 11, pp. 363-367.

Castro, M. de (2001): «Viveiro, monasterio de la Purísima Concepción», in S. L. Pérez López (coord.), El Monasterio de la Concepción, Viveiro, pp. 157-173 (existe copia de este trabajo en Estudios Mindonienses, 17).

Couceiro Freijomil, A. (1944): Historia de Puentedeume y su comarca, s.l.

Donapétry Iribarnegaray, J. (1947): «Doña María de las Alas Pumariño, fundadora del Convento de la Concepción de Vivero», Boletín de la Comisión provincial de Monumentos Históricos y Artísticos de Lugo, II, 21-22, pp. 298-302.

Donapétry Iribarnegaray, J. (1953): Historia de Vivero y su concejo, Vivero.

Fernández Gasalla, L. (2004): La arquitectura en tiempos de Domingo de Andrade. Arquitectura y sociedad en Galicia (1660-1712), Santiago de Compostela.

Fernández Gasalla, L. (2008): «La biblioteca del arquitecto Diego Ibáñez Pacheco y la recepción e interpretación de la tratadística italiana en la Galicia Oriental (16231694)», in XV Congreso Nacional de Historia del Arte (CEHA). Modelos, intercambios y recepción artística (de las rutas marítimas a la navegación en red). Palma de Mallorca, 20-23 de octubre de 2004, I, Palma de Mallorca, pp. 323-335.

Fernández Gasalla, L. (2009-2011): «Documentos sobre o mestre de arquitectura e escultura Bernabé García de Seares no Arquivo Histórico Provincial de Lugo (16811696)», Boletín do Museo Provincial de Lugo, 14, pp. 47-60.

Fernández Gasalla, L. (2009-2011): «O escultor e mestre de arquitectura Bernabé García de Seares (1670-1714)», Boletín do Museo Provincial de Lugo, 14, pp. 15-45.

García Oro, J. (2001): «La concepción de Viveiro en su contexto religioso. Un hogar mariano para la Galicia del Barroco», in S. L. Pérez López (coord.), El Monasterio 
de la Concepción, Viveiro, pp. 39-51.

Goy Diz, A. (1996): «La actividad de un maestro cántabro en tierras de Lugo: Diego Ibáñez Pacheco», Altamira, 52, pp. 223-261.

Lence-Santar y Guitián, E. (1910): Mondoñedo: El Convento de la Concepción, Mondoñedo.

López Calvo, A. (1994): «El frustrado convento de la Encarnación de Pontedeume, un antecedente del convento concepcionista de Mondoñedo», Estudios Mindonienses, 10, pp. 433-445.

Pardo Villar, A. (1947): «El Convento de Nuestra Señora de Valdeflores. (Apuntes históricos)», Boletín de la Comisión provincial de Monumentos Históricos y Artísticos de Lugo, III, 23-24, pp. 27-38.

Pérez Costanti, P. (1930): Diccionario de artistas que florecieron en Galicia durante los siglos XVI y XVII, Santiago.

Rodríguez Núñez, C. C. (1993): «El monasterio de Nuestra Señora de Valdeflores de Viveiro», Estudios Mindonienses, 9, pp. 441-539.

San Cristóbal Sebastián, S. (2001): Monasterio de la Concepción de Mondoñedo, Lugo.

Taín Guzmán, M. (1999): «Clasicismo y barroco en tierras mindonienses», Estudios Mindonienses, 15, pp. 469-518.

Trapero Pardo, J. (1949): «Un testamento y un inventario de objetos del siglo XVII», Boletín de la Comisión provincial de Monumentos Históricos y Artísticos de Lugo, III, 29-30, pp. 264-267. 